\title{
Effectiveness of Cognitive-Behavioral Group Therapy on Self-Concept of Visually Impaired Adolescents
}

\author{
Mahmood Yaghotian' ${ }^{1}$ Ali Akbar Soleimanian ${ }^{1 *}$, Hamid Darrodi ${ }^{1}$ \\ 1. Department of Counseling, Faculty of Human Sciences, University of Bojnord, Bojnord, Iran.
}

Citation: Yaghotian M, Soleimanian AA, Darrodi H. Effectiveness of cognitive-behavioral group therapy on self-concept of visually impaired adolescents. Iranian Rehabilitation Journal. 2016; 14(1):51-58. http://dx.crossref.org/10.15412/J.IRJ.08140108

http://dx.crossref.org/10.15412/J.IRJ.08140108

\section{Article info:}

Received: 10 Aug. 2015

Accepted: 29 Nov. 2015

\section{Keywords:}

Self-concept, Visually impaired, Cognitive-behavior counseling

\begin{abstract}
Objectives: The present study has been conducted to determine the effectiveness of cognitivebehavioral group-therapy on the development of visually impaired adolescents' self-concept.

Methods: This study is a semi-experimental pre-test and post-test model. The study population consisted of visually impaired male students of the primary and secondary high school at the Omid-e-Mashhad Educational Center for the Blind in the 2014-2015 academic year. Beck's Self-Concept Scale was used as a research tool, and 20 students with scores one deviation standard below the mean were randomly selected and divided into experimental and control groups. The experimental group received nine weekly sessions of cognitive-behavioral therapies, each of 90 minutes. The post-test data analysis was performed by conducting SPSS using descriptive statistics methods (mean and standard deviation for the study variables and tables) and inferential statistics methods (including Kolmogorov-Smirnov test, t-test for independent groups, Lewin test, and co-variance test).
\end{abstract}

Results: The results of covariance analysis revealed that the intervention of cognitive behavioral group counseling can significantly increase the self-concept among the participants of the experimental group.

Discussion: Cognitive-behavioral group counseling sessions can improve the self-concept of visually impaired adolescents. Moreover, positive self-concept will increase their social interaction and mental health.

\section{Introduction}

$\mathbf{I}$

$t$ has been a century since exceptional children have been taken into consideration in Iran. Exceptional children of different groups are currently undergoing training and rehabilitation services. Since visually impaired children are considered to be the nearest group to the ordinary people, paying attention to this group and their education is of foremost importance. Legal or statutory blindness defines a blind person as one who has best corrected visual acuity of 20/200 or less in the better eye or his visual board is too limited to see objects with an angle more than 20 degrees. Basically, individuals with a low vision possess

* Corresponding Author:

Ali Akbar Soleimanian, PhD

Address: Department of Counseling, Faculty of Human Sciences, University of Bojnord, Bojnord, Iran

Tel: +98 (915) 5844357

E-mail: soliemanian@gmail.com 
visual acuity between 20/70 and 20/200 in the better eye accompanied by corrections (e.g. glasses) [1].

Visual disability makes a person dependent on others. This is because blindness affects the cognitive and emotional development of children and adolescents by limiting and changing their range of experiences, decreasing the ability to move around, and decreasing the amount of controlling and making relationship with the environment [2]. An innate blind child has his own special experience from the world, which is different from that of other children with vision. He/she has to deal with the problems in life all by himself. All these rough experiences, stress, feelings of insecurity, and frustrations eventually affect the child's personality [3].

Sight (vision), one of the most important tools in recognition, has the greatest contribution to an individual's understanding, formation of concepts, and development of thinking. The lack of vision can affect our compatibility with the environment and can get us exposed to disorders and delayed mental development. Without vision, one can have a different perception and thought process, which can lead to varied emotion-al problems, incompatibility, depression, and low self-concept in visual impaired individuals $[4,5]$.

Adolescence is a critical and formative stage of an individual's social and psychological development. The need for emotional and affective balance, realization and appreciation of self-existence, acquiring social skills in making friends, self-recognition of healthy and efficient life, etc. are amongst the most important needs of adolescents. Thus, it is necessary to help adolescents grow and develop social skills that are needed for effective and constructive growth of the society. This developmental period can get disturbed due to few obstacles associated with low selfesteem, inferiority complex, and negative self-concept accompanied by feelings of anger and aggression thereby reducing the natural activities and social communications [6]. Behavioral problems, especially the social problems of blind adolescents, are related to low self-esteem, negative self-concept, and weak social skills [7].

Self-concept is a self-image and dynamic system that relates to the person's belief, value, interest, talent, and abilities, which in turn, determines the course of an individual's life [8]. Self-concept can be divided into positive and negative types. Positive self-concept shows that a person has been accepted as someone with strengths and weaknesses, and this acceptance will boost not only his/her self-confidence but also social relationships. The alternate version can be denoted as negative self-concept that includes psychologically unhealthy people [9]. Corte \& Zucker [10] stated that adolescents with negative self-concept tend to have anti-social behavior, and the risk of alcoholism, depression, anxiety, and aggression are more prominent in them. Positive self-concept is a protective factor among the adolescents against antisocial behaviors that leads to the initiation of the ability to say "no" to unpleasant activities.

Our behavior is the reflection of the way we are looked by the onlookers. Similarly, adolescents with sight impairment also generate negative self-image when the community and family members start looking at them from the angle of his/her disabilities. However, self-image can be made efficient and positive by increasing the self-consciousness level in an individual's ability. This can increase an individual's satisfaction and level of joy despite his/her physical differences. For a visually impaired person, the ability to accept his/her own disability is a key factor in obtaining positive self-concept and high self-esteem, appropriate social compatibility, and better expression. Most importantly, it is the main part of his own existence [11].

Despite a number of studies $[12,13]$ that refers to lower concepts and its components in the blind persons compared to sighted people, there are also other studies [1416] that approve lack of differences in self-concept of blind people and their normal counterparts. As well, Halder \& Datta [17] in their study, that has been conducted to investigate the meaning of self-concept in sighted and blind adolescents according to sex, concluded that sighted boys have higher self-concept scores than sighted girls. However, there are no significant differences in self-concept scores of blind boys and girls. Also, blind adolescents have lower self-concept than their sighted counterparts.

The most important variables of self-concept and compatibility in adolescents, as mentioned in various studies, include knowledge about professional talents, locus of control, intrinsic motivation, academic achievement, increasing the perceived ability, self-acceptance, increasing positive relationships with family and peers, decreasing depression, and increasing problem-solving abilities [18]. Sacks \& Wolfe [19] and Zebehazi and Smith [20] have stated that social and emotional skill training for adolescents with visual impairment is very important. To develop a suitable self-concept and empathy, there is a need for consultations, stress reduction programs, and interventions to improve personal and social skill development in visually impaired adolescents. Strengthening auditory imagery helps blind people in expressing their feelings in a 
socially acceptable way, which would eventually improve their self-esteem and create a positive self-concept [21].

The cognitive-behavioral method is one of the psychotherapy approaches that would increase consciousness and modify beliefs and attitudes. The basic assumption of this approach is that cognition influences on feelings and behavior. Moreover, it is believed that instead of events themselves, individuals respond to their cognitive representations. Cognitive-behavioral therapy (CBT) emphasizes on reducing the effects on inconsistent beliefs or feedbacks (Ellis quotes Shafiabadi and Naseri, 8). One of the most compelling reasons for CBT in schools is that it can be used as both treatment and prevention [22]. These therapies mainly focus on cognitive-emotional, behavioral, and social components of an individual, which makes it the foremost choice of researchers in prevention sciences and mental health improvement.

Therefore, this study attempts to study the effects of cognitive-behavioral therapy (CBT) method on selfconcept and its component in sight impaired adolescents.

\section{Methods}

This study is a semi-experimental research with pretest and post-test design. The cognitive-behavioral intervention was considered as the independent variable, and self-concept of the visually impaired adolescents was considered as the dependent variable.
The study population consisted of visually impaired male students studying in the primary and secondary high school at Omid-e-Mashhad' Educational Center for the Blind in 2014-2015 academic year. Initially, 72 students completed the Beck's Self-Concept Questionnaire. Of them, 20 students with total self-concept scores less than 76 (a deviation below the mean) were randomly selected and divided into experimental and control groups. Beck's Self-Concept Test was used in this research to test the students' self-concept. This scale examines five aspects of an individual's personality, i.e. intellectual ability, work efficacy, physical attractiveness, social skills, and virtues and vices.

Beck and colleagues (1985) reported 0.88 and 0.65 reliability coefficient using the test-retest method after one week and after three months intervals, respectively. As well, the internal consistency coefficient was reported as 0.80 for this scale. The questionnaire validity compared to Rosenberg's self-esteem questionnaire was reported as 0.55 [23]. Also, Hosseini and colleagues [24], was reached 0.91 Cronbach's Alpha for the scale.

The questionnaire scores of the randomly selected 20 visually impaired students, with 10 subjects in each group, were considered as pre-test scores. For the experimental group, the cognitive-behavioral therapy was administered in nine weekly sessions, each of 90 minutes (Table 1). The control group neither received any intervention nor participated in any training classes. After the

Table 1. Curriculum of CBT sessions.

\begin{tabular}{|c|c|}
\hline Session & Subjects \\
\hline First & $\begin{array}{l}\text { Members meeting each other and explaining the group about the process and rules of the session as well as the discuss- } \\
\text { ing the goals of the participants. }\end{array}$ \\
\hline Second & $\begin{array}{l}\text { Talking about self-concept, self-confidence, and characteristics of people with high self-confidence, characteristics of } \\
\text { automatic thoughts, and identifying them. }\end{array}$ \\
\hline Third & $\begin{array}{l}\text { Accepting your thoughts and feelings without rejecting and denying, speaking about your abilities and disabilities, seek- } \\
\text { ing feedback from each person towards the whole group and about himself at the beginning and end of the session. }\end{array}$ \\
\hline Fourth & $\begin{array}{l}\text { Presenting A-B-C theory, analyzing the relationship between unpleasant events, beliefs, and mood changes caused by } \\
\text { it, techniques of self-acceptance, self-esteem, not considering disabilities as limitations, and the members' feedback on } \\
\text { each other. }\end{array}$ \\
\hline Fifth & $\begin{array}{l}\text { Strengthening positive thinking, expressing features of people with positive thinking, avoiding pessimistic explanations, } \\
\text { and creating positive changes in life. }\end{array}$ \\
\hline Sixth & $\begin{array}{l}\text { Expressing examples of dependency and lack of confidence in life by members, feedback of members on each other, pos- } \\
\text { itive self-talk and self-induction techniques, explaining the downward arrow technique to identify negative core beliefs. }\end{array}$ \\
\hline Seventh & Effective ways of communication, assertiveness, and self-expression skill trainings by using role-playing technique. \\
\hline Eighth & Setting realistic and measurable goals for life. \\
\hline Ninth & $\begin{array}{l}\text { Reviewing meetings and summarizing the members' feedback about the changes felt during the session and about each } \\
\text { other. }\end{array}$ \\
\hline
\end{tabular}


completion of the sessions, question-naires were again distributed to the participants of both the experimental and control groups.

\section{Results}

The statistical description of pre-test and post-test selfconcept scores of the individuals is outlined in Table 2. It shows that the scores of mean and standard deviation in the experimental group at the pretest stage were 61 and 3 , respectively, whereas in the post-test stage, the scores increased up to 77 and 7, respectively. On the other hand, the scores in the post-test stage of the control group slightly increased in comparison to the pre-test stage.

Table 3 describes the scores of the experimental group based on different subscales, including physical attractiveness, intellectual ability, social skills, and work efficacy. In the experimental group, the average scores of post-test were found to be higher than that of the pretest. However, in the control group, the average scores of post-test remained constant or decreased compared to the pre-test scores. The "virtues and vices" score did not show any increase in the post-test stage.
In this study, two independent groups were compared based on self-concept and other subscales to investigate the normality of the score distributions in both the pre-test and post-test stages. Kolmogorov-Smirnov test was later conducted to decide whether the parametric or non-parametric tests should be utilized, and also to ensure about the adequate sampling size. In the meantime, Lewin and t-test for independent groups were conducted to ensure the equality of variances and lack of significant differences in the groups in the pre-test stage. The results are provided in Tables 4 and 5.

Table 4 indicates the significance level for self-concept and subscale scores and normal scores of both the pretest and post-test stages. Therefore, it was concluded that the sample size was adequate.

Table 6 shows that the obtained F-score for the pre-test stage was 23.62 , which was significant at $\mathrm{P}<0.01$. The pre-test, therefore, exerted its influence over the total score in post-test, as moderated in this model. Moreover, F-score for the influence of the independent variable was 22.65, which was significant at $\mathrm{P}<0.01$. Hence, group CBT influences the enhancement of self-concept among visually impaired adolescents and creates a significant

Table 2. Statistical description of pretest and posttest scores of self-concept among the individuals under study.

\begin{tabular}{cccccc}
\hline \multirow{2}{*}{ Group } & \multicolumn{3}{c}{ Pre-test } & \multicolumn{2}{c}{ Post-test } \\
\cline { 2 - 5 } & Mean & SD & Mean & SD \\
\hline Experiment & 61.70 & 3.40 & 2.14 & 77.00 & 7.36 \\
Control & 59.80 & 65.70 & Пranian Rehabilitation 『ournal
\end{tabular}

Table 3. Statistical description of pre-test and post-test based on different subscales.

\begin{tabular}{cccccc}
\hline \multirow{2}{*}{ Subscale } & Group & \multicolumn{2}{c}{ Pre-test } & \multicolumn{2}{c}{ Post-test } \\
\cline { 3 - 6 } & & Mean & SD & Mean & SD \\
\hline \multirow{2}{*}{ Physical attractiveness } & Experiment & 13 & 1.63 & 15.10 & 2.33 \\
& Control & 13.30 & 1.70 & 12.80 & 1.54 \\
Intellectual ability & Experiment & 13.60 & 2.01 & 15.80 & 2.04 \\
& Control & 12.80 & 1.75 & 13.20 & 1.31 \\
Social skills & Experiment & 12.70 & 2.90 & 16.10 & 2.13 \\
& Control & 13.80 & 1.39 & 12.90 & 1.10 \\
Virtues/vices & Experiment & 13.70 & 1.70 & 13.90 & 1.37 \\
& Control & 12.30 & 1.88 & 13.40 & 1.57 \\
Work efficacy & Experiment & 14.40 & 1.70 & 16.10 & 2.23 \\
\hline
\end{tabular}


Table 4. Investigating the normality of the distribution of self-concept and subscale scores in pre-test and post-test stages.

\begin{tabular}{cccccc}
\hline \multirow{2}{*}{ Subscale } & Group & & \multicolumn{2}{c}{ P } & \multicolumn{2}{c}{ Palue } \\
\cline { 3 - 6 } & & Pre-test & Post-test & Pre-test & Post-test \\
\hline \multirow{2}{*}{ Self-concept } & Experiment & 0.47 & 0.77 & 0.97 & 0.58 \\
& Control & 0.44 & 0.61 & 0.98 & 0.85 \\
Physical attractiveness & Experiment & 0.63 & 0.72 & 0.81 & 0.66 \\
& Control & 047 & 0.57 & 0.97 & 0.90 \\
Intellectual ability & Experiment & 0.81 & 0.48 & 0.52 & 0.97 \\
Social skills & Control & 0.48 & 1.07 & 0.97 & 1.99 \\
& Experiment & 0.76 & 0.58 & 0.60 & 0.88 \\
Virtues/vices & Control & 0.43 & 0.76 & 0.99 & 0.60 \\
& Experiment & 0.76 & 0.83 & 0.60 & 0.49 \\
Work efficacy & Control & 0.77 & 0.63 & 0.58 & 0.81 \\
& Experiment & 0.61 & 0.75 & 0.84 & 0.62 \\
\hline
\end{tabular}

K-S: Kolmogrov-Smirnov test score.

Iranian Rehabilitation Journal

Table 5. Examining the difference in mean score and the equality of variances in pre-test.

\begin{tabular}{ccccc}
\hline Subscale & Levin test (F) & P-value & $\mathbf{t}$ & P-value \\
\hline Self-concept & 3.81 & 0.06 & 1.49 & 0.15 \\
\hline Physical attractiveness & 0.04 & 0.82 & -0.40 & 0.69 \\
\hline Intellectual ability & 0.34 & 0.56 & 0.94 & 0.35 \\
\hline Social skills & 3.70 & 0.06 & -1.07 & 0.29 \\
\hline Virtues/vices & 0.03 & 0.84 & 1.74 & 0.09 \\
\hline Work efficacy & 2.63 & 0.12 & 1.54 & 0.13 \\
\hline
\end{tabular}

Iranian Rehabilitation Journa

difference in the mean scores of self-concept between the experimental and control groups. Besides, the cognitive-behavioral group-therapy also enhanced physical attractiveness, intellectual ability, social skills, and work efficacy among the visually impaired adolescents. However, it did not influence the Virtues/vices scores.

\section{Discussion}

This study was conducted to determine the effectiveness of group CBT on the self-concept of visually impaired adolescents. The results suggest that the program increased the self-concept and its components in the experimental group. Franken (1994) argued in his study that a growing body of research indicates that changes in self-concept are possible. In another research, Arip and his colleagues have stressed on the importance of self-concept and con- sistency in both academic and social life of adolescents, and thus, it is necessary to strengthen it in their lives in acceptable ways. Their findings proved that group CBT strength-ens the self-concept of adolescents, which is consistent with our study results. Our findings are also consistent with the results of other studies [25-28] that examined the effectiveness of group CBT on self-esteem and self-confidence in children and adolescents.

In cognitive terms, our study showed that CBT trainings can change the irrational thoughts and beliefs that have a strong emphasis on acceptance of disability, concealing blindness, using rehabilitation aids, and ignoring others sympathetic behaviors. All the efforts were intended to change the irrational beliefs to rational in these adolescents. The training programs reduced the irrational beliefs in the experimental group, thereby lead- 
Table 6. Pre-test and post-test results of covariance analysis between the two groups.

\begin{tabular}{|c|c|c|c|c|c|c|c|}
\hline Scale & Source & Sum of squares & df & Mean squares & F-score & P-value & Effect size \\
\hline \multirow{2}{*}{ Self-concept } & Pre-test & 330.38 & 1 & 330.38 & 23.62 & 0.0001 & - \\
\hline & Intervention & 316.82 & 1 & 316.82 & 22.65 & 0.0001 & 0.57 \\
\hline \multirow{2}{*}{$\begin{array}{c}\text { Physical attractive- } \\
\text { ness }\end{array}$} & Pre-test & 41.50 & 1 & 41.50 & 24.33 & 0.0001 & - \\
\hline & Intervention & 32.80 & 1 & 32.80 & 19.23 & 0.0001 & 0.53 \\
\hline \multirow{2}{*}{ Intellectual ability } & Pre-test & 3.33 & 1 & 3.33 & 1.13 & 0.30 & - \\
\hline & Intervention & 27.83 & 1 & 27.83 & 9.48 & 0.007 & 0.35 \\
\hline \multirow{2}{*}{ Social skills } & Pre-test & 33.58 & 1 & 33.58 & 31.35 & 0.0001 & - \\
\hline & Intervention & 69.92 & 1 & 69.92 & 62.27 & 0.0001 & 0.79 \\
\hline \multirow{2}{*}{ Virtues/vices } & Pre-test & 4.12 & 1 & 4.12 & 1.99 & 0.17 & - \\
\hline & Intervention & 0.06 & 1 & 0.06 & 0.03 & 0.85 & 0.002 \\
\hline \multirow{2}{*}{ Work efficacy } & Pre-test & 10.49 & 1 & 10.49 & 3.37 & 0.08 & - \\
\hline & Intervention & 20.79 & 1 & 20.79 & 6.69 & 0.01 & 0.28 \\
\hline
\end{tabular}

ing to an increase in self-concept. Physical assertiveness training is a behavioral training that modifies an individual's behavior while interacting with others as well as provides an opportunity for developing self-expression and personal ideas. Such changes can be regarded as a positive self-image and can induce the feelings of satisfaction, independence, power, positive self-concept, and high self-esteem in an individual.

Our results showed that implementing the independent variable in the experimental group increased the social skills that are consistent with the findings of Beik Mohammadi and colleagues. The increase in social selfconcept may be due to the assertiveness training programs and application of the acquired skills in real-life situations, which helped the blind students to achieve the necessary self-scrutiny.

Weak body language is a specific disability in visually impaired individuals because they have not learned the ways to express their feelings, emotions, and communicate through body movements by observing others. This inability may distance them from others. Moreover, staying away from normal children and having limited participation in different games because of their inability in understanding and interpreting other's message may limit their social relationship. Assertiveness and interpersonal skill training can improve their self-concept, self-esteem, and self-confidence.
The research findings show that having a positive attitude towards oneself and education (based on cognitivebehavioral therapy) and strengthening the self-concept can lead to an increase in the occupational (as well as academic) self-concept and motivate to be successful. These results are consistent with that of Kajbaf, Rezvani [29]. The academic self-concept and achievement motivation depends on the factors that people attribute to their successes. An individual, with a good self-image, feels that he is an able person, thinks confidently, and showcases a successful behavior to achieve higher self-esteem. On the contrary, an individual considering himself as an unsuccessful person remains academically below the level of his innate talents and abilities [30].

Our study also shows that the experimental group compared to the control group received higher scores on physical attractiveness component, which increased the physical self-concept in the experimental group. Physical attractiveness is associated with an individual's identity, and blind people undergo problems in exploring different aspects and executing different roles, and thus, experience unpleasant emotions. Identity and personality-related problems are not the reasons of inherent blindness; rather it is the results of social interactions and community attitudes towards them. Different emotions such as pity, caring, and extreme support does create difficult situations for them. People with positive physical self-concept have a good self-esteem, realistic view of their shortcomings and weaknesses, and feelings of capabilities and values. They are resistant and stable while 
facing real-life problems and psychological pressure, threats, and disasters [31].

\section{Conclusion}

Our study concludes that the visually impaired students can prove themselves to be more effective and useful members of the society. They should also get benefits from the same social and cultural rights and other advantages compared to their counterparts with vision. Considering the deficiencies in various areas, especially in the cognitive and interpersonal skills, the educational system should help the blind adolescents in overcoming their limitations by uplifting their character and propelling them towards independence and self-confidence through proper education programs.

\section{Acknowledgements}

The current research hasn't received any financial support.

\section{Conflict of Interests}

The authors declared no conflict of interests.

\section{References}

[1] Kauffman JM, Hallahan DP. Handbook of special education. Routledge: Taylor \& Francis; 2011.

[2] Khodabakhshi A. [The applications of theories of counseling and psychotherapy in rehabilitation of the disable people (Persian)]. Tehran: Danjeh Press; 2011.

[3] Narimani M, Soleimani E, Abolghasemi A. [A comparison of internal and external dimensions of thinking styles in blind and sighted students (Persian)]. Journal of School Psychology. 2012; 1(1):108-18.

[4] Baird SM, Mayfield P, Baker P. Mothers interpretations of the behavior of their infants with visual and other impairments during interactions. Journal of Visual Impairment and Blindness. 1997; 91(2):467-83.

[5] Qureshi Rad F, Bafandeh H. [The bases of professional identity and coping strategies in adolescents with visual impairment (Persian)]. Psychological Achievements, Chamran University. 2010; 4(2):113-34.

[6] Dadpour G, Tavakolizadeh J, Panahi Shahri M. [The effectiveness of rational-emotional group training on self-esteem and anxiety of gifted boy students (Persian)]. Journal of Research in Health. 2012; 2(1):36-43.

[7] Kef S. Psychosocial adjustment and the meaning of social support for visually impaired adolescents. Journal of Visual Impairment \& Blindness. 2002; 96(1):22-37.
[8] Shafi Abadi A, Nasseri G. [Theories of counseling and psychotherapy (Persian)]. Tehran: University Publication Center; 2012.

[9] Sareban H, Isamorad A, Tabibi Z. [Studying the effects of parenting attitudes in mental-social health (self-concept, social interaction) of teens (Persian)]. Journal of School Psychology. 2013; 2(3):97-124.

[10] Corte C, Zucker RA. Self-concept disturbances: Cognitive vulnerability for early drinking and early drunkenness in adolescents at high risk for alcohol problems. Addictive Behaviors. 2008; 33(10):1282-290.

[11] Berzonsky MD. Identity formation: the role of identity processing style and cognitive processes. Personality and Individual Differences. 2008; 44(3):645-55.

[12] Asadi J, Turabi S. [Comparison of assertiveness, Anxiety, depression and stress in blind and sighted people (Persian)] Journal of Exceptional Education. 2009; 13(2):3-13.

[13] Whit LG. Problem solving self efficacy community interaction, and employment of blind adults [PhD dissertation] Hawaii: Hawaii University; 2003.

[14] Bolat N, Dogangun B, Yavuz M, Demir T, Kayaalp L. Depression and anxiety levels and self-concept characteristics of adolescents with congenital complete visual impairment. Turkish Journal of Psychiatry. 2011; 22(2):77-83.

[15] Maleki Tabar A, Khoshkonesh A, Khodabakhshi Koulaei A. [Comparing the self-concept and social adjustment among blind and healthy male students (Persian)]. Zahedan Journal of Research in Medical Sciences. 2012; 13(10):33.

[16] Omrany A, Nori S. [Comparative study of the self concept and its components among sighted and blind students (Persian)]. Journal of Exceptional Education. 2005; 48(3):61-67.

[17] Halder S, Datta P. An exploration into self concept: A comparative analysis between the adolescents who are sighted and blind in India. British Journal of Visual Impairment. 2012; 30(1):31-41.

[18] Arip MA, Yusooff FB, Jusoh AJ, Samad NA. The effectiveness of cognitive behavioral therapy (CBT) treatment group on self-concept among adolescents. International Journal of Humanities and Social Science. 2011; 1(8):113-22.

[19] Sacks S, Wolffe KE. Teaching social skills to students with visual impairments: From theory to practice. New York: American Foundation for the Blind; 2006.

[20] Zebehazy KT, Smith TJ. An examination of characteristics related to the social skills of youths with visual impairments. Journal of Visual Impairment \& Blindness. 2011; 105(2):84-89.

[21] Ma Y, Han S. Neural representation of self-concept in sighted and congenitally blind adults. Brain. 2011; 134(1):235-46

[22] Corey M, Corey G, Corey C. Groups: process and practice. Boston: Cengage Learning; 2003.

[23] Fathi Ashtiani A. [Psychological tests (Persian)]. Tehran: Besat Publication; 2009.

[24] Hosseini M. [The correlation of family functioning dimensions and self-concept of adolescent smokers in Zanjan (Persian)]. Journal of Health Promotion Management. 2012; 1(4):61-68. 
[25] Bahrami H, Banihashemian K. [Effective method of selfesteem and assertiveness on The blind student (Persian)]. Research on Exceptional Children. 2010; 10(2):153-161.

[26] Beikmohamadi M, Tarkhan M, Akbari B. The effect of group cognitive-behavioral training and coping with stress on social adjustment and self-concept of high school female students. Knowledge \& Research in Applied Psychology. 2013; 13(4):41-50

[27] Ismaili M. [The effectiveness of social skills training by cognitive behavioral group in the increase of girls' self-esteem and assertiveness with addicted parents (Persian)]. Research on Addiction. 2010; 16(3):56-41.

[28] Jalali D, Nazari A. [Effects of social learning model training on self-esteem, self-confidence, self assertiveness and academic achievement in third grade students of intermediary schools (Persian)]. Journal of Research in Behavioural Sciences. 2009; 7(1):43-53.

[29] Kajbaf M, Rezavani F. [Effects of cognitive-behavioral, educational attainment, high school girls in Isfahan (Persian)]. Journal of Knowleg \& Research in Applied Psychology. 2007; 27(35):49-58.

[30] Hosseini Dowlatabadi F. [The self concept of academic achievement of students with an emphasis on the duties of teachers (Persian)]. Peyvand. 2007; 34(4):25-34

[31] Khoshkam Z, Malakpour M, Mowlavi H. [Effectiveness of social problem-solving skills of students with a visual impairment (Persian)]. Research on Exceptional Children. 2008; $8(2): 141-56$ 